\title{
Staying within planetary boundaries as a premise for sustainability: On the responsibility to address counteracting sustainable development goals
}

\author{
Heidi Rapp Nilsen \\ Department of Philosophy and Religious Studies, Faculty of Humanities, NTNU, \\ heidi.r.nilsen@ntnu.no
}

DOI: http://dx.doi.org/10.5324/eip.v14i1.2863

(cc) BY

This is an open access article distributed under the terms of the Creative Commons

Attribution 4.0 International License, which permits unrestricted use, distribution, and reproduction in any medium, provided the original author and source are credited.

Sustainable development, as explained through the three pillars of environment, society and economy, is a well-known concept and has been used extensively in recent decades. There is finally a growing acknowledgement that environmental sustainability is the prerequisite for achieving the other two pillars of societal and economic sustainability. Nevertheless, there is a tendency to not explicate the negative interactions between the pillars of sustainability, as in the interlinkages between the UN's sustainable development goals. In this paper, we draw attention to a method for explicating both reinforcing and counteracting goals. This is a conceptual paper but with short, illustrative examples from different levels of the $R \& D$ sphere on how this method can be used: one example is at the project level, two are from financiers of R\&D projects, and the other is at the UN level. Finally, a longer discussion on relevant ethical guidelines is presented. This paper addresses the responsibility to recognize when and how sustainability goals counteract each other through two key actions. The first action is to identify transgressions of global ecological system boundaries and the resulting serious consequences for trading on environmental sustainability. The second involves bringing to the fore relevant ethical guidelines from the Norwegian National Research Ethics Committee. An update of these guidelines is suggested to reflect recent research on the transgression of planetary boundaries and the consequences for a safe operating space for humans on Earth.

Keywords: Environmental sustainability, ethical guidelines for research, UN sustainable development goals, counteracting goals

\section{Introduction}

Humankind has affected and changed nature for as long as we have existed as a species. Nevertheless, the changes that we are causing now have a breadth and pace 
that are unprecedented (Stenøien and Andersen 2018; McNeill 2000). Unlike only a century ago, we now have advanced knowledge of the effects that we are causing through the recognized framework of planetary boundaries (PB). This framework defines a safe operating space for humanity based on the intrinsic biophysical processes that regulate the stability of the Earth system (Rockström, Steffen, Noone, Persson, Chapin, Lambin, ... Foley 2009; Steffen, Richardson, Rockström, Cornell, Fetzer, Bennett,... Sörlin 2015).

In the same period that the work on the PB framework progressed, the UN developed its 17 sustainable development goals (SDGs), which the UN General Assembly adopted in 2015 (United Nations 2015a). These goals are now being extensively used in policymaking, and by industry and academia. However, there is a tendency to explicate single SDGs or an SDG that enables or reinforces another SDG, while leaving out negative interactions between SDGs (United Nations 2017, European Commission 2016, Forskningsrådet 2017). In this paper, we highlight the obligation, especially within research, to address when and how sustainability goals counteract each other. We do this by addressing 1) transgressions of the planetary boundaries and the consequences of the trade-offs between SDGs, and in light of these transgressions, 2) bringing to the forefront relevant ethical guidelines from the Norwegian National Research Ethics Committee (2018a; 2018b). We suggest an update of these guidelines to reflect recent research findings, such as the transgression of planetary boundaries for a safe human existence on Earth.

Sustainable development has been an extensively used and well-known concept for 30 years, since the publication of the report titled Our common future (World Commission on Environment and Development 1987). The operationalization of the concept has to a large degree been the three-pillar approach of sustainable environment, sustainable society and sustainable economy (Folke, Biggs, Norström, Reyers and Rockström 2004, Holden, Linnerud, Banister, Schwanitz and Wierling 2018: 24), although other pillars, such as institutions, culture and/or politics have sometimes been added (Spangenberg 2002, Keitch, Kua and Skjerven 2016, Lafferty and Langhelle 1999). In most policy and business communities, the three pillars - also referred to as aspects or dimensions - have either been given equal weight (Folke and others 2016), or the economic pillar has been given priority (Nilsen 2010, Giddings, Hopwood and O'Brien 2002, Kallio, Nordberg and Ahonen 2007). However, there is now growing knowledge and acknowledgement regarding the importance of environmental sustainability as a premise for economic and social sustainability and even human existence, as projected by the PB framework. SDGs aspire to find a coherent way of thinking about how, for instance, poverty, innovation and climate change fit together as intertwined social, economic and environmental targets (United Nations 2015a). The goals depend on each other, but the dependency and interactions are both positive and negative. One SDG may reinforce the other or reduce the effect of a third SDG (Hickel 2019, Gupta and Vegelin 2016, Pongiglione 2015). We therefore draw attention to a method for explicating both reinforcing and counteracting goals. This is a conceptual paper but with short, illustrative examples from different levels of the R\&D sphere: one at the project level, two on financiers of R\&D projects, and one at the UN level. Finally, a longer discussion on relevant ethical guidelines for research is presented.

We want to raise awareness about a warning regarding the use of the SDGs as formulated by Nilsson, Griggs and Visbeck (2016: 320): "If countries ignore the 
overlaps and simply start trying to tick off targets one by one, they risk perverse outcomes." The perverse outcome that we address in this paper, and hence want to avoid, is to contribute to the transgression of planetary boundaries. From the PB framework, we know that biosphere-based sustainability is a prerequisite to achieving sustainability within societies and economies (Folke and others 2016). Disturbingly, it is estimated that humanity has already transgressed at least four of the nine defined boundaries: climate change, loss of biodiversity, biogeochemical flows of phosphorus and nitrogen, and land-system change (Steffen and others 2015). We have entered the age of the Anthropocene, signifying that the planet is leaving the geological epoch of the Holocene, as our influence outweighs the impact of natural forces on the functioning of the Earth system (Crutzen 2002).

Furthermore, in this paper, sustainability refers to biosphere-based sustainability. In the three-pillar approach, this means that environmental sustainability is the prerequisite for a sustainable society and a sustainable economy. ${ }^{1}$

In the next section we present the problem of counteracting SDGs and the suggested method for addressing such problems. The following section focuses on the planetary boundaries for a safe operating space for humanity, linked to counteracting SDGs. We then present examples from different levels of the R\&D sphere and discuss them in relation to the suggested method. Lastly, before summing up, we present relevant guidelines and suggest updates to reflect that research has an ethical obligation to contribute to a biosphere-based sustainability.

\section{Counteracting goals}

The overall aim of SDGs is to promote human dignity and prosperity while safeguarding the Earth's vital biophysical processes and ecosystem services (United Nations 2015a). SDGs originated at the 2012 Rio conference in the final declaration, 'The Future We Want' (United Nations 2012). At the more formal level, SDGs are replacing the United Nations' millennium development goals (MDGs), which the UN member states agreed to try to achieve by 2015. The United Nations' Millennium Declaration, signed in 2000, committed world leaders to work towards eight goals to combat poverty, hunger, disease, illiteracy, environmental degradation, and discrimination against women and to develop a global partnership for development. However, MDGs prolonged the traditional marginalistic approach of focusing on one natural resource at a time (Folke and others 2016). Therefore, the SDG agenda represents a new way of thinking about how issues such as poverty, innovation and climate change are intertwined. Implicit in the SDG logic is that the 17 goals depend on each other, but without specifying exactly how.

Figure 1 is the official short version of the goals. All SDGs have longer titles that are followed by specific targets, totalling 169 targets. As an example, the full title of SDG 14 is 'Conserve and sustainably use the oceans, seas and marine resources for sustainable development,' and target 14.1 states the following: "By 2025, prevent and significantly reduce marine pollution of all kinds, in particular from land-based activities, including marine debris and nutrient pollution" (United Nations 2015a). These SDGs can be mutually reinforcing, but they can also be contradictory, as 
pointed out by several scholars. Gupta and Vegelin (2016) claim that there are trade-offs in favour of economic growth over social and ecological viability. Pongiglione (2015) argues for the prioritization of SDGs that are compatible and that facilitate other sustainability objectives. Hickel (2019) adds to this literature by quantifying that economic growth, as outlined in SDG 8, is at odds with human development objectives that rely on equity both within nations and between them. Nilsson and others (2016) suggest an approach in which the influence of one SDG on another is organized on a scale consisting of the following seven levels: indivisible, reinforcing, enabling, consistent, constraining, counteracting, and cancelling. This scale is illustrated in Table 1, which also offers examples of SDGs influencing other SDGs. A strength of this method is that it allows for a wider sphere of interactions to be assessed, beyond the more well-known economic growth versus sustainable society and sustainable environment discourse.

Figure 1. The United Nations' sustainable development goals
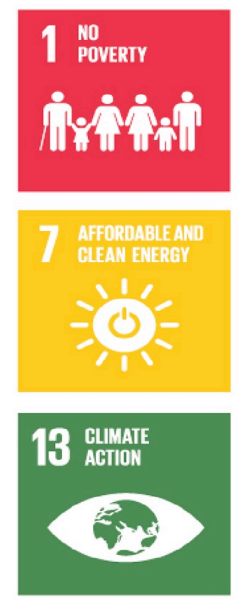
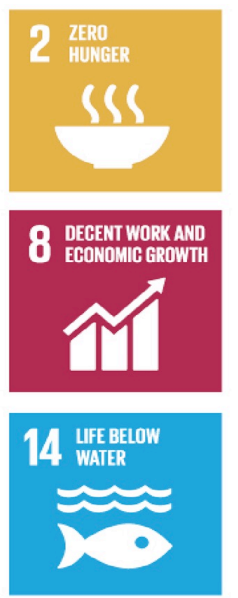
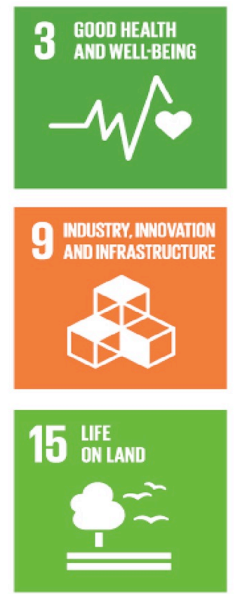
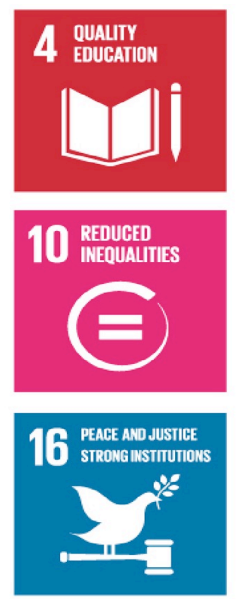
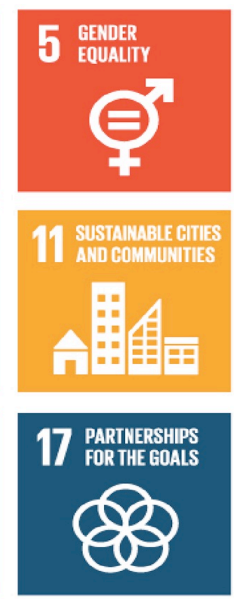
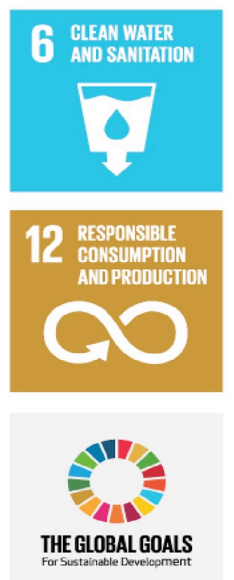

In the following section, we present the planetary boundary framework in more detail and discuss this situation in relation to trade-offs between SDGs in research.

\section{Safe operating space for humanity}

The Earth system has offered a safe operating space for providing favourable conditions for complex human societies. This has taken place in the relatively stable 11,700-year-long epoch called the Holocene, the only state that we know for certain can support contemporary human societies. The planetary boundaries framework, first launched in 2009 (Rockström and others 2009), is based on assessing critical processes that regulate the functioning of the Earth system. This framework demonstrates that we are leaving the Holocene, as we already have transgressed four of nine identified planetary boundaries - climate change, biosphere integrity, biogeochemical flows of phosphorus and nitrogen, and land-system change. In other words, we are moving out of the safe operating space for humanity (Steffen and others 2015; Raworth 2017). The other five identified boundaries that have not yet been transgressed are global freshwater use, ocean acidification, chemical pollution, aerosol loading and stratospheric ozone depletion. With each transgression of one boundary, the thresholds for the others may be lower, making the destabilization of the Earth system more probable (Rockström and others 2009). 
Table 1. Interactions among the United Nations' sustainable development goals (Nilsson and others 2016, p. 321)

\begin{tabular}{|c|c|c|c|}
\hline Interaction & Name & Explanation & Example \\
\hline+3 & Indivisible & $\begin{array}{l}\text { Inextricably } \\
\text { linked to the } \\
\text { achievement of } \\
\text { another goal }\end{array}$ & $\begin{array}{l}\text { Ending all forms of } \\
\text { discrimination against women } \\
\text { and girls is indivisible from } \\
\text { ensuring women's full and } \\
\text { effective participation and equal } \\
\text { opportunities for leadership. }\end{array}$ \\
\hline+2 & Reinforcing & $\begin{array}{l}\text { Aids the } \\
\text { achievement of } \\
\text { another goal }\end{array}$ & $\begin{array}{l}\text { Providing access to electricity } \\
\text { reinforces water-pumping and } \\
\text { irrigation systems. } \\
\text { Strengthening the capacity to } \\
\text { adapt to climate-related hazards } \\
\text { reduces losses caused by } \\
\text { disasters. }\end{array}$ \\
\hline+1 & Enabling & $\begin{array}{l}\text { Creates } \\
\text { conditions that } \\
\text { further another } \\
\text { goal }\end{array}$ & $\begin{array}{l}\text { Providing electricity access in } \\
\text { rural homes enables education } \\
\text { because it makes it possible to } \\
\text { do homework at night with } \\
\text { electric lighting. }\end{array}$ \\
\hline 0 & Consistent & $\begin{array}{l}\text { No significant } \\
\text { positive or } \\
\text { negative } \\
\text { interactions }\end{array}$ & $\begin{array}{l}\text { Ensuring education for all does } \\
\text { not interact significantly with } \\
\text { infrastructure development or } \\
\text { conservation of ocean } \\
\text { ecosystems. }\end{array}$ \\
\hline-1 & Constraining & $\begin{array}{l}\text { Limits options } \\
\text { on another goal }\end{array}$ & $\begin{array}{l}\text { Improved water efficiency can } \\
\text { constrain agricultural irrigation. } \\
\text { Reducing climate change can } \\
\text { constrain the options for energy } \\
\text { access. }\end{array}$ \\
\hline-2 & Counteracting & $\begin{array}{l}\text { Clashes with } \\
\text { another goal }\end{array}$ & $\begin{array}{l}\text { Boosting consumption for } \\
\text { growth can counteract waste } \\
\text { reduction and climate } \\
\text { mitigation. }\end{array}$ \\
\hline-3 & Cancelling & $\begin{array}{l}\text { Makes it } \\
\text { impossible to } \\
\text { reach another } \\
\text { goal }\end{array}$ & $\begin{array}{l}\text { Fully ensuring public } \\
\text { transparency and democratic } \\
\text { accountability cannot be } \\
\text { combined with national-security } \\
\text { goals. Full protection of natural } \\
\text { reserves excludes public access } \\
\text { for recreation. }\end{array}$ \\
\hline
\end{tabular}


In this paper, we take as a premise that we want to avoid transgressing the planetary boundaries further and to stay within those boundaries that we have not yet transgressed.

Climate change and biosphere integrity are 'core' boundaries based on their fundamental importance for the Earth system. The crossing of one or more of the other boundaries may seriously affect human well-being and may predispose the transgression of a core boundary but does not by itself lead to a new state of the system of this planet. Of these two core boundaries, biosphere integrity is the least known. The biosphere is the global ecological system integrating all living beings, their relationships, and their dynamic interplay with the atmosphere, water cycle, biogeochemical cycles and the dynamics of the Earth system as a whole. Diversity in the biosphere provides resilience to terrestrial and marine ecosystems (Biggs, Schlüter, Biggs, Bohensky, BurnSilver, Cundill, ... West 2012; Cumming, Olsson, Chapin and Holling 2013). The biosphere not only interacts with the other planetary boundaries but also increases the capacity of the Earth to persist in a given state under changes in these other boundaries.

Even though the transgression of global boundaries yields a new situation with respect to the possibility of achieving biosphere-based sustainability, there has been scientific knowledge for a long time that such effects eventually emerge. In 1896, the Swedish chemist Arrhenius calculated that a doubling in the concentration of $\mathrm{CO}_{2}$ would increase the mean or middle global temperature by approximately 5 degrees Celsius (Barrett, 2003, p. 363). The capacity of the biosphere as part of the complex dynamics of the Earth system to sustain human development also has a long legacy and was made explicit with, for example, the development of ecological economics. Here, the economy is a subsystem of the biosphere, and it is explicit that the increase in scale and the connectivity and speed of the globalized world shapes the biosphere and our own future in profound ways (Odum 1971, Costanza, R. 1989). However, only recently has there been a broader and more systematic approach to identifying, evaluating, and quantifying the risks of abrupt planetarylevel shifts due to the overshooting of key Earth system parameters (Rockström and others 2009; Steffen and others 2015).

In light of the severe situation of continuous contributions to (further) transgressing the PBs, we argue for the ethical obligation of research to assess and articulate when there is a risk of trade-offs between the sustainability pillars and, in particular, when the trading is done at the cost of environmental sustainability. Such assessments can be made through SDGs and the suggestions of Table 1, as four of the SDGs are goals that contribute to a resilient biosphere (Folke and others 2016): climate action (number 13), life below water (number 14), life on land (number 15) and clean water and sanitation (number 6). Of course, positive and negative contributions to the other SDGs should also be expressed, but our concern in this paper is primarily that biosphere-based sustainability is the foundation upon which the pillars of a sustainable society and economy rest.

It can be challenging to assess and articulate possible interactions in $R \& D$ between sustainability pillars. If this is outside a researcher's or project's area of expertise, then the project team must be expanded to include relevant expertise to address these questions. The level and depth of the assessments will have to vary, depending on various factors such as the character of the project, the type and strength of interactions, and the recipient's need and processing of the information. 
This paper does not offer a description of more specific requirements for level and depth, beyond the examples presented in the next section.

More importantly, such an assessment gives the researchers an opportunity to revise the project idea and project plan to avoid or reduce trade-offs. Possible negative interactions that cannot be resolved by revising the particular research project still need to be explicated, so that they can be addressed elsewhere, such as by other research programmes or politically. Until negative interactions are stopped and as long as these interactions irreversibly contribute to transgressing PBs, the research project is not appropriate for a biosphere-based sustainability.

\section{Examples and discussion of method}

In this paper, we discuss the method of Table 1 in relation to examples of the different levels of the $R \& D$ sphere: an international $R \& D$ project pursuing innovative solutions for marine plastic waste, two different programmes for financing R\&D projects, and one example from the UN level.

The Circular Ocean (2015-2018) was an R\&D project seeking to inspire enterprises and entrepreneurs to realize hidden opportunities in discarded fishing nets and ropes in the Northern Periphery and Arctic region. A part of the Circular Ocean was to call a competition for innovative project ideas to recycle plastic waste from the fishing industry ${ }^{2}$. The contestants were asked, amongst other questions, to explain the following in their application: "How does the solution contribute to the UN's sustainable development goals?" (Circular Ocean 2018). This question gives no incentive to use the limited space of a maximum of 100 words to describe how their innovative projects might constrain or even cancel another goal. Some contest applicants may have described negative interactions, ${ }^{3}$ but that does not change the point of this example: The question for contestants should ask for both positive and negative effects on other SDGs. Moreover, the contestants could have been asked to reflect on the strength of such interactions, the possibility of these interactions actually occurring, and the possibility of negative interactions outweighing the positive effects of the innovation.

Our objective is not that the contestants, or others discussing interlinkages between SDGs, must arrive at a specific figure on the total effect of interactions, based on figures from the leftmost column in Table 1. More important is to use the examples in the other columns as a guide for how a discussion of interactions can be carried out. Table 1 addresses the macro level, whereas we argue that these considerations should also be taken into account at the project level when sustainability is an issue.

Other considerations beyond Table 1 include discussing the reversibility of the interrelations. The innovative solution of repurposing discarded fishing nets can be used as an example. A new product on the market made from discarded fishing nets leads to enhanced greenhouse gas emissions from production and transportation if this new product is manufactured in addition to other products, instead of as a replacement for other products. In that case, this new product puts an irreversible constraint on SDG 13 'Climate action'. It may be difficult to revise a project to avoid this interrelation, and naturally it is not appealing to researchers to highlight such negative implications. However, if trade-offs are not resolved at the project level, it 
is even more important to articulate them so that they can be addressed elsewhere, for instance by financiers of $\mathrm{R} \& \mathrm{D}$. It should therefore also be in the interest of investment programmes of $\mathrm{R} \& \mathrm{D}$ projects to ask for considerations and transparency regarding negative interactions. Accordingly, we have looked briefly at two financiers, the Northern Periphery and Arctic Programme and the Norwegian Research Council.

The Northern Periphery and Arctic Programme 2014-2020 cofinanced the Circular Ocean and has been evaluated with regard to its possible overall environmental effect. "To ensure the viability of the approach, there is a need to ensure a balanced consideration of the different dimensions of sustainable development, preventing the domination of one dimension over the others" (Clement 2014:54). However, no specification has been provided on how to ensure this balance. As this programme was not completed by the time this paper was written, how and if such a consideration is undertaken remains to be seen. We argue that such a consideration requires having information on interactions at the project level, including details on direction, possibility, strength and reversibility. This is increasingly important the larger and more complex research projects become, as increasing complexity makes it even more difficult for people who are not part of the project team to assess relevant interactions.

The Norwegian Research Council says in its strategy for sustainability that applicants will have to describe how the project will contribute to increased sustainability when this is of relevance (Forskningsrådet 2017). We argue that when sustainability is an issue, it is equally important to point out to the applicants that there are inherent contradictions at the macro level between many of the SDGs and that projects must therefore reflect any possible contributions to reduced sustainability. This should spur applicants to revise their projects to decrease negative interactions as far as possible. Moreover, financiers or specific research programmes should perform an overview and evaluate the balance between the different dimensions of sustainability or between SDGs. An aggregate imbalance in disfavour of biosphere-based sustainability can then be acted upon, for instance, by earmarking more means for projects that contribute to biosphere-based sustainability.

In discussing counteracting SDGs in a research project, it may be helpful to distinguish between the effect of an R\&D project and the impacts of the insights generated through research or the scaling-up of what has been developed. The impacts of insights generated through the R-part in $\mathrm{R} \& \mathrm{D}$ may be difficult to assess, whereas the scaling-up of the D-part is probably easier.

Many other striking examples can be found, where negative interactions between the UN's SDGs are not accounted for, including at the macro level within the UN itself. A report reviewing one SDG, developed by 12 UN entities, uses the scale of Table 1, but only the positive interactions are presented (United Nations 2017). All 17 SDGs are placed on this scale, but no possible negative cross-cutting interactions are portrayed. In the text accompanying the table, the reader is made aware that the sustainability of life below water (e.g., SDG 14) can be traded off by other pillars of sustainability - here, economic growth - if necessary changes are not made. Continuous emissions of greenhouse gases are creating warmer seas and killing coral reefs and may serve as an example of a change needed to arrive at environmentally sustainable oceans. Nevertheless, the text accompanying the table 
does not reflect that the necessary economic changes are of enormous dimensions, from global structural changes to individual attitudes. At the global level, the viability of achieving an expansion of the ocean economy based on a 'sustainable use of the oceans' - as explicitly stated in the SDG 14 title - has yet to be demonstrated.

\section{Ethical guidelines for research}

The process that we suggest in the previous section can be seen as a responsibility ${ }^{4}$. In this section, we examine whether and how this responsibility is specified in ethical guidelines for research and, in particular, in the Norwegian ethical guidelines for research. These guidelines were created by the Norwegian National Committees for Research Ethics, which is an independent administrative agency under the Norwegian Ministry of Education and Research. There are four different committees, and according to their webpages, the committees are to be impartial advisory bodies providing guidance and advice on research ethics and where the guidelines are seen as important tools for promoting good scientific practice in the Norwegian research system. In this section, we present the paragraphs that are most relevant with regard to the planetary boundaries and suggest a few examples of proposed revisions ${ }^{5}$ to bring them in line with environmental sustainability as biosphere-based sustainability.

The Norwegian National Committees for Research Ethics have created seven different guidelines for research. One of these is 'Guidelines for research ethics in science and technology, ${ }^{3}$ issued by the National Committee for Research Ethics in Science and Technology (NENT). With regard to the theme of this paper, we examine the chapter titled 'The obligations of research to society', paragraphs 2 and 8 (the Norwegian National Committees for Research Ethics 2016):

\section{Research should be compatible with sustainable development.}

Researchers and research institutions have a collective responsibility to contribute to sustainable development and the preservation of biological diversity. The concept of "sustainability" encompasses economic, social, institutional, and environmental aspects.

The second sentence in the citation above from NENT states that sustainability encompasses four aspects. ${ }^{7}$ We propose to add that the environmental aspect is a foundation for the other sustainability aspects, in line with the PB framework. Biosphere capacity serves as the foundation for human well-being, and human wellbeing is embedded in and rests on a resilient biosphere (Folke and others 2016; Steffen and others 2015).

Furthermore, the first sentence of this citation stresses the importance of preserving biological diversity. Nevertheless, biological diversity is defined as something that happens in addition to sustainable development, with the 'and' between them: "(...) contribute to sustainable development and the preservation of biological diversity." This can be interpreted in two ways, which we denote as a) and b) below:

a. Preserving biological diversity is a responsibility, regardless of sustainable development. The concept of sustainable development is by and large anthropocentric, in the sense that only human beings have moral standing. 
However, many different non-anthropocentric approaches grant other living beings and non-living substances, such as water and mountains, a moral standing (DesJardins, 2006). In these approaches, biological diversity - or the parts that in sum make up biological diversity - has intrinsic value. Biological diversity is not to be valued according to how it contributes to sustainable development. If this is a correct interpretation, then we suggest no changes to this sentence.

b. Biological diversity is a necessary part of sustainable development and is to be preserved without trade-offs with the other pillars and other SDGs. This is an approach in line with biosphere-based sustainability. However, this approach does not encompass the complexity of biosphere-based sustainability, as biological diversity alone cannot keep us within a safe operating space for humanity. If biological diversity is included because it is a necessary part of biosphere-based sustainability, then several other necessary parts should also be listed. Most importantly, the other three defined boundaries are already in a critical state: climate change, biogeochemical flows of phosphorus and nitrogen, and land-system change (Steffen and others 2015). If listing the necessary aspects of environmental sustainability is not a goal, specifying biological diversity should be removed. Then, it is especially important to make the change proposed above in the second sentence and state that the environmental aspect is a foundation for the other sustainability aspects. Otherwise, removing 'preservation of biological diversity' weakens biospherebased sustainability in this paragraph from NENT.

The next paragraphs from NENT address researchers' responsibility to assess uncertainty and strive to observe the precautionary principle. Both these paragraphs are of relevance for assessing counteracting SDGs. We suggest that NENT consider explicitly including the problem of counteracting SDGs in these paragraphs as an overall purpose and also because so many R\&D projects already refer to SDGs.

\section{Researchers must clarify the degree of uncertainty in their research and evaluate the risk associated with the research findings}

Researchers must clarify the degree of certainty and precision that characterises their research results. They must be particularly meticulous about clarifying the relative certainty and validity range of their findings. In addition to presenting knowledge critically and in context, researchers must strive to point out any risk and uncertainty factors that may have a bearing on the interpretation and possible applications of the research findings. Communicating the relative certainty and validity of knowledge is part of a researcher's ethical responsibility and effort to achieve objectivity. Where possible, researchers should also use appropriate methods for demonstrating the uncertainty of the research. Research institutions have an obligation to teach these methods to their employees and students.

In paragraph 8 cited above, the second-to-last sentence asks for appropriate methods for demonstrating the uncertainty of the research. When uncertainty is related to the pillars of sustainable development or specifically related to achieving 
one or more of the SDGs, Table 1 above offers a method for discussing that kind of uncertainty.

\section{Researchers must strive to observe the precautionary principle}

Where there is plausible, but uncertain knowledge to the effect that a technological application or a development of a research field may lead to ethically unacceptable consequences for health, society, or the environment, the researchers in the field in question must strive to contribute knowledge that is relevant for observing the precautionary principle. This means that researchers must work together with other relevant parties in observing the precautionary principle. The precautionary principle is defined here as follows: "When human activities may lead to morally unacceptable harm that is scientifically plausible but uncertain, actions shall be taken to avoid or diminish that harm." This principle is important for a large part of science and technology research, and researchers have a shared responsibility for ensuring that evaluations are based on the precautionary principle and contribute to avoiding or diminishing harm.

Paragraph 9 cited above can also be operationalized in relation to SDGs. Researchers must strive to contribute knowledge relevant to assess plausible but uncertain knowledge of ethically unacceptable consequences of a technological application or development of a research field. This can be framed by assessing possible counteracting SDGs, the possibility of the interactions occurring, reversibility of interrelations, and finally the possibility of negative interactions outweighing the positive effects of the technological application or development of a research field. Furthermore, paragraph 9 already says that researchers have a responsibility to avoid or diminish harm.

\section{Conclusion}

The United Nations sustainable development goals (SDGs) have been widely welcomed, and in academia, they have sparked a new way of approaching the complex issue of sustainability. However, the 17 SDGs have inherent contradictions at the macro level, and it seems to be overlooked that this has implications at lower levels, such as in research programmes and $R \& D$ projects. We argue that possible negative effects for sustainable development should be critically addressed.

The two main reasons for this obligation are, first, the global biosphere-based situation for a continuous safe operating space for humanity, where the core planetary boundaries of climate change and biosphere integrity are being transgressed (Steffen and others 2015). We therefore need to plan and implement $\mathrm{R} \& \mathrm{D}$ that contribute to preserving ecosystems that are critical for maintaining the function of the Earth system. This capacity is called a biosphere-based sustainability and is the premise for a sustainable society and a sustainable economy.

We highlight a method by Nilsson and others (2016) on how to discuss the possible constraining, counteracting and cancelling of SDGs. We expand on how this method should be used by offering examples from different levels relevant to research, such as an international $\mathrm{R} \& \mathrm{D}$ competition on recycling fishing gear and financiers of R\&D. Key features in this method are to reflect on the strength of both 
positive and negative interactions between goals, the possibility and reversibility of the interactions and whether negative interactions may outweigh the positive effects of an action. Interactions that put further pressure on planetary boundaries contribute, however marginally, to driving us further away from the Holocene and are a concern for all of humanity. This needs to be articulated because it then gives researchers the ability to revise or stop the project or to pass this concern on to their financiers or to politicians.

The other reason to critically address possible negative interlinkages is a responsibility to comply with ethical guidelines for research. We have looked into the Norwegian ethical guidelines and relevant paragraphs, which are guided by the terms of sustainable development, uncertainty and the precautionary principle. We suggest how these ethical guidelines should be updated to reflect the recent developments within sustainability science and how they can be linked to address the problem of counteracting SDGs.

The discourse field of sustainable development has become so broad and divergent that it has largely become noncommittal (Nilsen 2010). The tendency to gloss over tricky trade-offs within this complex sphere may lead SDGs to suffer the same destiny. The stakes are high; progress in economic and social sustainability can be lost, as our planet ceases to function for the benefit of the global population.

\section{Acknowledgements}

This paper is part of a pilot program HAVANSVAR Blue Humanities Initiative, which is an NTNU Oceans Pilot on ethical, cultural, communicative, narrative and historic dimensions of Ocean-related research and innovation. NTNU Oceans is one of NTNU's four strategic research areas. The author of this paper thanks Circular Ocean for the opportunity to be a judge in the competition that provided insight into the theme of this paper. The author also thanks the anonymous reviewers for valuable feedback in developing this paper.

\section{Notes}

${ }^{1}$ Often, the terms sustainability and sustainable development are used interchangeably (Wilderer 2007), as we also do in this paper. This has induced critique that the obvious needs of developing countries to develop are excluded (Barkemeyer, Holt, Preuss and Tsang 2014). It is outside the scope of this paper to discuss this critique, beyond stating an explanation for using sustainability in this paper: we have concluded that environmental sustainability is the requisite foundation for the other two pillars. The consequences of this premise, for research on SDGs, have been the primary points of discussion in this paper.

${ }^{2}$ Looking for an R\&D project to use as an example in this paper, we chose to use this project because the author of this paper knew the project from being an external judge in this competition. It is important to note that all the information provided in this paper is public. Moreover, the critical light on Circular Ocean in this paper only has to do with the particular part concerning the use of the SDGs in the competition. We have not investigated other parts of the project and thus have no reason to question any other aspects of Circular Ocean. 
${ }^{3}$ As a judge in this competition, this author was able to evaluate entrants and how they described the effect on SDGs. The project management of Circular Ocean was asked to release data so that contestants' contributions on SDGs could be analysed and aggregated anonymously in this paper. This request was declined and of course complied with.

${ }^{4}$ In this paper we are using 'obligation' and responsibility in the later section. The nuance between these two words is described as follows in a well-recognized web resource: "[...] a responsibility is something you can be held accountable for. ... Being responsible means you have a sense of moral or ethical duty to something or someone which may imply an obligation to do something. An obligation is simply a mandate to do something that does not connote any moral or ethical dimension." (english.stackexchange.com)

${ }^{5}$ By the time this paper is published, these guidelines may already have been updated, possibly according to some of the recommendations in this paper. An earlier version of this paper was presented at the ELSA conference in Norway in November 2018 (https://www.ntnu.no/blogger/elsa/). A representative from The Norwegian National Research Ethics Committees was present, and in March 2020 she asked for and was given the suggestions in writing, for a possible revision of the guidelines.

6 The remaining six guidelines are for medical and health research, the social sciences, law and the humanities, internet research, human remains, research ethics checklist, and use of animals in research.

${ }^{7} \mathrm{We}$ have not used a separate pillar or aspect of institutions in our previous discussion. It is the biosphere as the foundation for all other pillars of sustainability that is the main point we raise. NENT refer to aspects, not pillars, but this does not change the main point: the biosphere as the foundation for the other aspects of sustainability.

\section{References}

Barkemeyer, R., Holt, D., Preuss, L. and Tsang, (2014). What happened to the development in 'sustainable development'? Sustainable Development, 22(1): 15-32. https://doi.org/10.1002/sd.521

Biggs, R., Schlüter, M., Biggs, D., Bohensky, E.L., BurnSilver, S., Cundill, G., ... West, P.C. (2012). Toward principles for enhancing the resilience of ecosystem services. Annual Review Environmental Resources 37: 421-448. https://doi.org/10.1146/annurev-environ-051211-123836

Circular Ocean (2018). Downloaded September 2018 from: http://www.circular ocean.eu/competitions/

Clement, K. 2014. STRATEGIC ENVIRONMENTAL ASSESSMENT OF THE NORTHERN PERIPHERY AND ARCTIC PROGRAMME 2014-2020. European Policies Research Centre, University of Strathclyde. Downloaded September 2018 from http://www.interreg-npa.eu/fileadmin/Programme _Documents/NPA_Programme_SEA_Report.pdf

Costanza, R. (1989). What is ecological economics. Ecological Economics, 1(1): 1-7. https://doi.org/10.1016/0921-8009(89)90020-7

Crutzen, P. (2002). Geology of Mankind. Nature 415: 23. https://doi.org/10.1038/ $415023 a$ 
Cumming, G. S., Olsson, P., Chapin III. F. S., Holling, C. S. (2013). Resilience, experimentation and scale mismatches in socialecological systems. Landscape Ecol. 28: 1139-1150. https://doi.org/10.1007/s10980-012-9725-4

DesJardins, J. R. (2006), Environmental ethics: an introduction to environmental philosophy (4th ed.). Belmont, Calif.: Thomson Wadsworth.

European Commission (2016). Next steps for a sustainable European future. European action for sustainability. Strasbourg, 22.11.2016 COM(2016) 739 final . Downloaded March 2020 from https://ec.europa.eu/transparency/ regdoc/rep/1/2016/EN/COM-2016-739-F1-EN-MAIN.PDF

Folke, C., Biggs, R., Norström, A. V., Reyers, B. \& Rockström, J. (2016). Socialecological resilience and biosphere-based sustainability science. Ecology and Society 21(3):41. http://dx.doi.org/10.5751/ES-08748-210341

Forskningsrådet 2017. Forskning for borekraftig samfunns- og noeringsutvikling. Forskningsrådets strategi for boerekraft 2017-2020. Downloaded March 2020 from https://www.forskningsradet.no/om-forskningsradet/publikasjoner/ 2017/forskning-for-barekraftig-samfunns--og-naringsutvikling/

Giddings, B., Hopwood, B. \& O’Brien (2002). Environment, economy and society. Fitting them together into sustainable development. Sustainable Development, 10(4), 187-196. https://doi.org/10.1002/sd.199

Gupta, J., \& Vegelin, C. (2016). Sustainable development goals and inclusive development. International Environmental Agreements: Politics, Law and Economics, 16(3), 433-448. https://doi.org/10.1007/s10784-016-9323-z

Hickel, J. (2019). The contradiction of the sustainable development goals: Growth versus ecology on a finite planet. Sustainable Development 2019; 1-12. https://doi.org/10.1002/sd.1947

Holden, E., Linnerud, K., Banister, D., Schwanitz, V.J. \& Wierling, A. (2018). The Imperatives of Sustainable Development. Needs, Justice, Limits. Earthscan from Routledge, London and New York. https://doi.org/10.4324/ 9780203022177

Kallio, T.J., Nordberg, P. \& Ahonen, A. (2007). Rationalizing Sustainable Development - a Critical Treatise. Sustainable Development 15: 41-51. https://doi.org/10.1002/sd.292

Keitch, M.M., Kua, H.W. \& Skjerven, A. (2016). Special Issue: The Cultural Dimension of Sustainability and Resilience. Sustainable Development, 24(5), 273-343. https://doi.org/10.1002/sd.1627

Lafferty, W.M.\& Langhelle, O. (eds) (1999). Towards Sustainable Development: On the Goals of Development and the Conditions of Sustainability. Basingstoke, UK, Palgrave Macmillan.

McNeill, J.R. (2000). Something new under the sun: an environmental history of the twentieth century. W.W.Norton, New York, USA.

Neumayer, E. (2003). Weak versus strong sustainability: exploring the limits of two opposing paradigms ( $2^{\text {nd }}$ ed.). Cheltenham: Edward Elgar.

Nilsen, H.R. (2010). The joint discourse 'Reflexive Sustainable Development' From Weak towards Strong Sustainable development. Ecological Economics, 69 (3): 495-501. https://doi.org/10.1016/j.ecolecon.2009.11.001

Nilsson, M., Griggs, D. and Visbeck, M. (2016). Map the interactions between Sustainable Development Goals. Nature 534: 320-322. https://doi.org/ $10.1038 / 534320 \mathrm{a}$ 
Odum, H. T. (1971). Environment, power, and society. Wiley-Interscience, New York.

Raworth, K. (2017). Doughnut Economics: Seven Ways to Think Like a 21st-Century Economist. Chelsea Green Publishing, White River Junction, Vermont.

Rockström, J., W. Steffen, K. Noone, Å. Persson, F. S. Chapin, III, E. Lambin, ... Foley, J. (2009). Planetary boundaries: exploring the safe operating space for humanity. Ecology and Society 14(2): 32. https://doi.org/10.5751/ES-03180140232

Pongiglione, F. (2015). The need for a priority structure for the Sustainable Development Goals. Journal of Global Ethics, 11(1), 37-42. https://doi.org/10.1080/17449626.2014.1001912

Spangenberg, J.H. (2002). Environmental space and the prism of sustainability: Frameworks for indicators measuring sustainable development. Ecological Indicators, 2, 295-309. https://doi.org/10.1016/S1470-160X(02)00065-1

Steffen, W., Richardson, K., Rockström, J., Cornell, S. E., Fetzer, I., Bennett, E. M., ...Sörlin, S. (2015). Planetary boundaries: guiding human development on a changing planet. Science 347:6223 http://dx.doi.org/10.1126/science.1259855

Stenøien, H. K. \& Andersen, R. (2018). Arten som forandret alt: Historien om menneskets erobring av naturen. Stenersens forlag.

The Norwegian National Research Ethics Committee (2014). General guidelines for research ethics. Last updated in September 2014. Downloaded in September 2018 from: https://www.etikkom.no/en/ethical-guidelines-for-research/ general-guidelines-for-research-ethics/

The Norwegian National Research Ethics Committee (2016). Guidelines for research ethics in science and technology. Last updated in June 2016. Downloaded in September 2018 from: https://www.etikkom.no/en/ethicalguidelines-for-research/guidelines-for-research-ethics-in-science-andtechnology/the-obligations-of-research-to-society/

The World commission on Environment and Development (1987). Our common future. Oxford University Press.

United Nations, 2012. “The Future We Want." Downloaded March 2020 from https://sustainabledevelopment.un.org/futurewewant.html

United Nations, 2015a. "Sustainable Development Goals. 17 Goals to transform our world." Downloaded August 2018 from https://www.un.org/ sustainabledevelopment/sustainable-development-goals/

United Nations, 2015b. "Millennium Development Goal 8 Taking Stock of the Global Partnership for Development.

MDG Gap Task Force Report 2015.”Downloaded September 2018 from http://www.un.org/millenniumgoals/pdf/MDG_Gap_2015_E_web.pdf

United Nations, 2017. "High Level Political Forum Thematic review of SDG 14: Conserve and sustainably use the oceans, seas and marine resources for sustainable development."

Background note developed by members of ECESA Plus as a coordinated contribution by the UN system to the 2017 HLPF in depth review of SDG 14 . Co-leads: FAO and UNESCO/IOC with contributions from OHRLLS, ITU, World Bank Group, ILO, UN Habitat, UN Women, UNEP, UNDP, UNIDO, WHO and UN-DESA. 
Wilderer, P.A. (2007) Sustainable water resource management: The science behind the scene. Sustain. Sci. 2: 1-4. https://doi.org/10.1007/s11625-007$0022-0$ 